\title{
"A MORTE E A MORTE DE QUINCAS BERRO DÁGUA", HISTÓRIA E LITERATURA: \\ DIÁLOGOS, SINGULARIDADES E POSSIBILIDADES DE \\ ANÁLISE
}

\author{
The Two Deaths of Quincas Wateryell": \\ HISTORY AND LITERATURE: \\ DIALOGUES, SINGULARITIES AND POSSIBILITIES OF ANALYSIS
}

\author{
Anderson Teixeira Renzcherchen ${ }^{1}$ \\ Silvéria da Aparecida Ferreira ${ }^{2}$
}

\begin{abstract}
RESUMO: Este artigo apresenta uma reflexão sobre os campos da História e da Literatura e suas aproximações. Entendemos a Literatura enquanto fonte, testemunho e evidência histórica. Para sustentar essa afirmação, buscamos na abertura historiográfica, promovida pela escola dos Annales e pela vertente da Nova História Cultural, as aproximações e possibilidades dessa relação. Pontuamos algumas singularidades da escrita histórica e da literária, bem como as apropriações e diálogos possíveis das produções literárias pela História. Por fim, analisamos a obra $A$ morte e a morte de Quincas Berro Dágua publicada pela primeira vez em 1959, do renomado escritor Jorge Amado, discussão na qual tentamos compreender o contexto social do autor e da obra, a fim de abranger os sentimentos, as angústias, percepções de mundo, mentalidades, mesmo não sendo nossa intenção inicial, atentamos para os estereótipos presentes na obra e sobre a sociedade baiana, da década de 1950, que ainda se perpetuam no discurso social.
\end{abstract}

Palavras-chave: História; Literatura; Fonte Histórica; Jorge Amado.

\begin{abstract}
This article presents a reflection on the fields of History and Literature and their approaches. We understand literature as a source, testimony and historical evidence. To support this affirmation we searched on the historiographical opening, promoted by the school of the Annales and the source of New Cultural History, the approaches and possibilities of this relation. We highlighted some singularities of the historical and the literary writing, as well as the appropriations and possible dialogues of the literary productions for History. Finally, we analyzed the literary work The Two Deaths of Quincas Wateryell published for the first time

1 Doutorando em Educação (PUCPR). Mestre em História (UNICENTRO). Graduado em História (UNICENTRO-Irati). Membro do Grupo de Estudos: História e Políticas da Educação e a Formação de Professores. E-mail: a.renzcherchen@gmail.com.

2 Professora da Rede pública e privada de ensino básico. Mestre em Educação (UNICENTRO). Especialista em "História, Arte e Cultura" (UEPG) e em "Educação Infantil" pela Universidade Positivo. Graduada em História (UNICENTRO-Irati) e Pedagogia (UNICESUMAR). E-mail: silveria f@hotmail.com.
\end{abstract}


in 1959, from the brazilian writer Jorge Amado, and we tried to understand the social context of the author and the literary work, in order to cover the feelings, distresses, perceptions of world, mentalities. And even if it was not our initial intention, we observed the stereotypes in the literary work and in the bahian society from the 1950's that are still present in the social speech.

Keywords: History; Literature; Historical source; Jorge Amado.

\section{Introdução}

A escrita da História trabalha, apropria e valida a cada dia novas fontes. Porém, essa forma abrangente de conceber a História consistiu em um trabalho árduo e lento de mudança paradigmática na ciência da História. No século XIX, permeado pelo pensamento positivista, eram consideradas fontes apenas os vestígios oficiais, documentos com vínculo formal, estatal e ligado a grandes nomes e acontecimentos políticos. O marxismo foi uma das correntes teóricas que questionou a hegemonia positivista, amalgamando o classicismo na forma de escrever a História. Contudo, a grande virada acontece com a Escola dos Annales, nas primeiras décadas do século $X X$.

O surgimento da Escola dos Annales, em 1929, marcou a discussão de novas formas de escrever a História, desvencilhando do domínio positivista e questionando-o. A busca por novos caminhos foi pautada pela tentativa de uma melhor compreensão da História a partir das mentalidades, objetivando a construção historiográfica baseadas nas estruturas para a compreensão social.

Nesta nova perspectiva, os historiadores dedicaram-se a validar um novo método, com a possibilidade de novas fontes, objetos, temas e abordagens. A ampliação de fontes e a abertura interdisciplinar ficaram evidentes na terceira geração dos Annales, pelo comando de Le Goff (2003), que considerava toda atividade humana como História e toda produção humana como fonte histórica. Ainda, segundo Barros (2013), Le Goff foi um dos autores que mais dialogou com as fontes literárias, contribuindo, principalmente, na História medievalista. É nesse contexto, por volta dos anos 1970, que a terceira geração dos Annales incorpora a 
Literatura como fonte histórica. As evidências nas obras literárias possibilitaram analisar a sociedade e os sentimentos dos sujeitos, as suas representações, simbologias e mentalidades coletivas, questões que são tratadas na vertente historiográfica da Nova História Cultural.

Dessa forma, além de trazer apontamentos sobre a incorporação da Literatura como fonte aos estudos históricos, esse trabalho busca responder as inquietações sobre como as aproximações entre História e Literatura são possíveis, quais possibilidades desse encontro, por fim realizamos a análise de uma obra literária enquanto fonte para compreender aspectos da realidade brasileira, especialmente baiana, da segunda década do século $\mathrm{XX}$.

\section{Abertura historiográfica: literatura como fonte}

A escrita da História vem se modificando, desde a tentativa de legitimação da História como ciência, ancorada no positivismo do século XIX. Os historiadores do século XX apresentaram, ao campo historiográfico, várias mudanças intelectuais. A abertura historiográfica, presente no movimento da escola dos Annales, representou uma nova configuração na produção da História, novas abordagens, novas fontes, novos objetos e problemas. Interessa-nos, principalmente, a terceira geração desse movimento complexo, que compreende discussões ocorridas desde 1970.

Diferente das duas primeiras, a terceira geração dos Annales é composta por vários historiadores, que em um trabalho coletivo interessaram-se por escrever a História "às avessas", valorizaram o que não estava determinado fisicamente e que na historiografia fora dado atenção, como as representações, o simbólico, as mentalidades, os sonhos, a loucura, o odor, entre tantos outros temas. Para Peter Burke (1991), ocorre na historiografia o deslocamento da narrativa dos privilegiados da sociedade para a História dos pequenos grupos, dos "vencidos".

Burke (1991), destaca que nesse contexto alguns historiadores franceses utilizaram de fontes literárias para compreender as mentalidades, como, por exemplo, a escrita de Rabelais por Febvre. As obras literárias já esboçavam, com composições ficcionais de enredo, o cotidiano e as 
mentalidades dos camponeses, de pequenos grupos menos favorecidos e sem destaque social. A multiplicidade iconográfica presente na Literatura auxiliou os historiadores a compreenderem questões cotidianas da vida dos sujeitos históricos, que muitas fontes formais não possibilitavam.

Voltando-nos para o Brasil podemos notar que a realidade se assemelha. Literatos como Jorge Amado (que será destacado adiante), escrevem sobre o cotidiano do povo, enredos populares, sem figuras políticas e heróis de destaque, tratam de pessoas comuns. As produções literárias de Jorge $\mathrm{Amado}^{3}$ são consideradas parte do movimento modernista que ocorre a partir de 1930 e segue até o final do século ${ }^{4}$ na Literatura. Já na historiografia, essa transição e adaptação de análises com novas fontes ocorre depois que essas obras já tinham sido produzidas, um dos motivos que leva historiadores da Nova História a se apropriarem dessas fontes para compreender outros tempos e espaços.

Como vertente historiográfica da Nova História, temos o que convencionamos chamar de "Nova História Cultural", nos anos de 1970, que fomentou a alteração nas formas de interpretação da História. Segundo Sandra Jatahy Pesavento (2004), o que passa a ocorrer consiste em uma renovação das correntes e campos de pesquisa, assim como uma transformação nos temas e objetos analisados, abrangendo uma multiplicidade de novas fontes até então desconsideradas, bem como a utilização de velhas fontes alicerçadas em novos questionamentos.

Inicialmente as novas correntes da História Cultural pensaram a escrita e leitura, aspectos do "texto", do qual compreenderam que a História é uma narrativa que constrói uma representação sobre o passado. A "tríade" - escrita, texto e leitura - permite a veiculação de representações, portanto é essencial no processo de produção das análises e da Escrita da História, visto que se passou a considerar a subjetividade do

\footnotetext{
3 Tomamos Jorge Amado aqui como modelo, mas outros exemplos são possíveis. Justificamos a escolha desse autor e de uma de suas obras, que será analisada posteriormente, logo à frente.

4 Sendo sua última obra publicada após sua morte intitulada Hora da Guerra - crônicas de 2008.
} 
historiador presente em todos os procedimentos, buscando a superação do mito da neutralidade e objetividade cientifica (PESAVENTO, 2004).

Na perspectiva da História Cultural é possível pensar as relações do discurso e do real e aproximá-las com outros campos, como, por exemplo, o da Literatura, sem perder a legitimidade da ciência histórica, mas para compreender as "relações possíveis entre a representação narrativa e o seu referente, questão central para a História Cultural" (PESAVENTO, 2004, p. 71).

Assim, a História Cultural rompe com a perspectiva historiográfica do século XIX, embora não desconsidere esses trabalhos. Desta forma, a escrita comporta mensagens e significados, que podem ser interpretados de diversas formas pelos diferentes sujeitos, negando a neutralidade da ciência. Torna-se preocupação da História compreender as "percepções dos indivíduos no tempo, quais os seus valores, aspirações, modelos, ambições e temores" (PESAVENTO, 2004, p. 71), considerando o historiador como ser subjetivo e também leitor. Leitor da realidade que é por si só dinâmica, portanto, acontece uma virada paradigmática que passa a entender a História como descontínua, mutável, passível de várias interpretações e capaz de diálogos profícuos com outras áreas do conhecimento.

Como evidenciado, as perspectivas da Nova História, em especial a vertente da Nova História Cultural, permitiram um leque imenso de novas possibilidades de abordagens historiográficas, rompendo com a escrita da História apenas por meio de documentos oficiais, grandes eventos e heróis, negando a neutralidade da ciência, mas validando seu método e estatuto de cientificidade. Embora com alguns limites, como toda e qualquer corrente teórica, incorporou à escrita novos elementos, novas fontes e abordagens (PESAVENTO, 2004). Nesse sentido, as obras literárias passam a ser compreendidas como fontes com potencial para auxiliar na escrita da História que contemple aspectos do cotidiano dos grupos sociais.

Em defesa da fonte literária, Sidney Chalhoub e Leonardo Pereira (1998) atestam que a Literatura, assim como qualquer obra humana, não é atemporal, a-histórica, ou inexplicável, pelo contrário, é um produto humano, de determinado tempo e espaço que possui historicidade. Deste 
modo, pode ser entendida enquanto problema histórico a ser explorado, pois a obra literária é para os historiadores um "testemunho histórico" (CHALHOUB; PEREIRA, 1998).

Todo testemunho histórico traz evidências para a escrita da História, ou seja, contribui para compreendermos aspectos da temporalidade e espacialidade dos sujeitos históricos presentes na fonte. Assim, como um processo criminal, uma carta, um diário, uma foto, o texto literário é um testemunho que produz evidências. Chalhoub e Pereira (1998) supõem o questionamento sobre a validade da obra literária, já que está permeada de elementos criados e entendidos como "fictícios", em resposta afirmam:

[...] ao historiador resta descobrir e detalhar com igual afinco tanto as condições de produção de uma página em livro de atas, ou de um depoimento em processo criminal, quanto as de um conto, crônica ou outra peça literária. Cabe o mesmo interrogatório sobre as intenções do sujeito, sobre como este representa para si mesmo a relação entre aquilo que diz e o real, cabe desvendar aquilo que o sujeito testemunha sem ter a intenção de fazê-lo, investigar as interpretações ou leituras suscitadas pela intervenção (isto é, a obra) do autor; enfim é preciso buscar a lógica social do texto. O bê-á-bá do oficio do historiador social é o mesmo, na análise da fonte literária, parlamentar, jornalística, jurídica, iconográfica, médica, ou seja lá o que mais (CHALHOUB; PEREIRA, 1998, p.8).

Por mais objetivas que tentem ser as produções humanas, encaradas pelo historiador como fonte histórica, são permeadas de intenções dos sujeitos que as produziram, não há neutralidade. Ao historiador cabe trabalhar com a premissa da subjetividade, desconfiar, estranhar e questionar qualquer fonte. No caso da fonte literária, deve ponderar sobre as características do contexto em que foi escrita, compreender as intenções do processo de produção e do sujeito que a produziu, ou seja, o próprio literato. Além disso, como determinados processos históricos são produzidos e subjetivados na obra por meio dos personagens/sujeitos, situações e enredos criados pelo autor (CHALHOUB; PEREIRA, 1998). 
Nesse sentido o diálogo da História e da Literatura fora, aos poucos, tornando-se possível e a aproximação das áreas demostrando ter potencialidade, cada qual com sua especificidade teórica e metodológica, mas articulando-se em busca de explicações mais coesas da realidade. Sendo assim, a Literatura contempla a criação imaginária, enquanto a História dialoga com as fontes, mas não deixa de ser uma narrativa da interpretação do sujeito que a produz. Desta maneira, uma acrescenta a outra já que ambas são representações do passado, retomaremos a frente essa discussão.

\section{Apropriações e usos da Literatura para a História}

Objeto da nossa discussão, a Literatura vêm sendo entendida enquanto instrumento e fonte dotada de potencial na historiografia, o que de certa forma reflete no Ensino de História, quando alguns professores utilizam-na buscando romper com o tradicionalismo e o método da memorização de conteúdo, no qual a disciplina de História e a própria escola se encontram, em que a aula é baseada puramente no uso do livro didático, quadro e giz (NASCIMENTO, 2005, p. 1).

O diálogo entre Literatura e História vem acontecendo com bastante êxito, pois na própria historiografia ou mesmo em trabalhos ligados ao Ensino de História, podemos notar na produção de artigos e anais de Simpósios em eventos que tratam dessa temática.

Santos (2009), realiza uma investigação que contempla, em sua dissertação de mestrado em História Social na Universidade Estadual de Londrina, a análise de como o Ensino de História e a Literatura foram trabalhadas e divulgadas, a partir de 1979 até 2007. Santos (2009), tem por base os anais do Simpósio Nacional de História - ANPUH, Encontro Nacional de Perspectivas do Ensino de História e Encontro Nacional de Pesquisadores do Ensino de História. Em sua pesquisa realiza um estudo detalhado das publicações de anais desses eventos e demonstra os caminhos da aproximação da Literatura e da História nas últimas décadas do século XX e início do XXI. 
Juntamente com o interesse pela pesquisa e divulgação, os eventos cresceram, bem como as abordagens utilizando História e Literatura. Conforme Santos (2009), a partir dos anos 1990, as análises que levam em consideração essas duas áreas tiveram um aumento significativo, nos Simpósios da ANPUH, por exemplo, sempre representaram de 2 a $3 \%$ dos trabalhos (com exceção de 1991 que foi 17,5\% dos trabalhos). Outros eventos, como o Encontro Nacional de Pesquisadores do Ensino de História e Perspectivas para o Ensino de História, também contemplam discussões acerca dessa temática, o que acabou dividindo as publicações, já que esses destinam-se para discussões da formação de professores, do ensino, de questões da disciplina escolar, inclusive de novas fontes e abordagens para o Ensino de História e para o estudo do Ensino de História, ou seja, as formas teóricas e metodológicas de pesquisas sobre o Ensino de História.

Conforme Santos (2009, p. 98), "percebemos que existe o interesse por parte dos pesquisadores e uma melhor aceitação dos trabalhos que procuram aproximar a Literatura do Ensino de História". Quase dez anos após essa pesquisa, é possível afirmar que esse campo de análise está, aos poucos, como qualquer outro, se consolidando. A Literatura tem sido fonte de análise historiográfica e também recurso didático nas salas de aula.

No texto História e Literatura: fontes literárias na produção historiográfica recente no Brasil, Camilotti e Naxara (2009), refletem sobre os usos da Literatura na historiografia, e suas aproximações e distanciamentos, nos últimos 30 anos. Segundo as autoras, a Literatura e a História surgiram como campos disciplinares em um contexto particular, o da modernidade. Ao esboçarem o desenrolar da historicidade da Literatura e da História, as autoras afirmam que o entrecruzamento dessas duas áreas é muito mais profundo que a apropriação da Literatura como fonte pela História, haja vista que a própria escrita da História pode levar traços literários. Isso por que:

[...] num extremo, o literário é tomado como substrato de inquirição pelo historiador, tendo em vista a reconstituição do que é identificado pelo nome de História, como algo que o 
antecede; no outro, o literário é tomado como substrato para o escrutínio de percepções, representações, figurações, por meio das quais se busca os movimentos de instituição de imaginários e da própria temporalidade enquanto tal (CAMILOTTI; NAXARA, 2009, p.28).

São modos de operação diferentes, no primeiro a Literatura pode ser encarada como um elemento da própria escrita historiográfica, no sentido de que a forma como o historiador narra o passado perpassa por invenções e criações que deixam o texto com cunho literário, a História seria, então, Literatura, como autores pós-modernos afirmam. Por outro lado, o historiador pode encarar as obras literárias como fonte. Quando o historiador toma a produção literária como objeto para responder questões que a historiografia e os documentos oficiais não dão conta, como sentimentos, pensamentos, mentalidades de determinada sociedade ao seu tempo. Essa segunda forma é a perspectiva adotada nesse ensaio.

\section{História e Literatura: aproximações e divergências dos campos em debate}

O caráter científico da narrativa histórica tem sido atacado nas últimas décadas, um exemplo significativo constitui-se na discussão do método desconstrucionista de Hayden White. White afirma que o passado só existe na maneira como é descrito pelos historiadores, a História seria, então, uma criação literária (ASSIS; CRUZ, 2010, 114). Contrário a essa perspectiva, o historiador Jörn Rüsen (2001) esforça-se na defesa do caráter cientificamente legítimo da escrita da História.

À vista disso o que faz o pensamento histórico ciência é o modo específico de "constituir sentido quanto a experiência no tempo, mediante o narrar" (RÜSEN, 2015, p. 59). Tomando por referência o trato que se dá ao passado no ato de narrar, torna-se muito raso simplesmente medir a História com a régua das ciências duras. O método é somado aos procedimentos cognitivos do historiador, não podendo, assim, meramente escrever o que pensa e lhe convém. 
No caso da história, a constatação é bem simples: conhecimento histórico científico se funda na pesquisa, e pesquisa é um procedimento regulado por critérios universalmente aceitos. Ela extrai de dados da experiência, existentes empiricamente, processos temporais, aos quais confere a forma de uma "história" baseada na experiência. 0 suprassumo desses critérios, que regulam o processo do conhecimento enquanto pesquisa, é chamado de "método histórico". (RÜSEN, 2015, p. 60)

Segundo Rüsen (2015) a História possui, portanto, uma forma específica de olhar para o passado, o pensamento histórico é regulado pelo método científico. O estatuto científico da História é assegurado pelo cuidado que o historiador tem de ter ao fundamentar a experiência obtida e a interpretação mediante a pesquisa.

O historiador tem a tarefa de construir uma narrativa sobre o passado aceitável cientificamente, o que quer dizer que os métodos de análise das fontes limitam sua imaginação sobre o que foi esse passado. Assim:

O historiador continua tendo o compromisso com as evidências na sua tarefa de reconstruir o real, e seu trabalho sofre o crivo da testagem e da comprovação, mas a leitura que faz de uma época é um olhar dentre os possíveis a serem realizados (PESAVENTO, 1998, p. 21).

Entendemos que a História e a Literatura são campos de conhecimento distintos, legítimos e que possuem suas singularidades, todavia acreditamos no potencial da aproximação das áreas. Neste trabalho, buscamos relacionar a História e a Literatura como complementares, sendo a Literatura uma fonte histórica que pode contribuir para a historiografia.

Como outrora mencionado, a perspectiva que corroboramos entende que as narrativas histórica e literária se diferem, embora ambas trabalhem com aspectos da realidade e do tempo. A História tem a obrigação de interpretar as fontes, porém há um consenso entre os historiadores da Nova História, de que mesmo trabalhando com a empiria não se pretende a verdade absoluta, contudo o historiador tem o compromisso com a 
interpretação pautada nos dados da realidade, dessa forma, objetiva narrar o que aconteceu. Já a narrativa literária possibilita transcender os dados das fontes, ou seja, a interpretação pode ultrapassar os dados da realidade e incorporar elementos fictícios, estéticos, sentimentos, imaginários, etc, elementos que vão para além das fontes, pois não tem o compromisso com a realidade, assim sendo narra o que poderia ter acontecido (ARISTOTELES, 2000).

Pesavento (1998) certifica que o mais condizente com a perspectiva da Nova História Cultural seria a substituição da ideia de "veracidade" pela "verossimilhança". O que considera os limites, mas valida ambas as formas de construir a realidade, visto que tanto a narrativa histórica quanto a literária comportam a preocupação com a verossimilhança, a ficção seria, assim, outra forma de conceber e captar a realidade, mas não seu avesso. O que torna a Literatura uma aliada em potencial na escrita e no Ensino de História.

Aristóteles (2000), considera a arte uma possibilidade de interpretação da realidade, Ihe atribuiu legitimidade, embora não esteja preocupada com a interpretação mais "real" dessa realidade. Posto isto, destaca que não cabe ao poeta narrar exatamente o que aconteceu, mas o que poderia ter acontecido, condições, possibilidades de acordo com a necessidade.

Na Literatura o elemento fictício auxilia para que a História possa ser mais completa, inclusive detalhando as nuances da personalidade do (a) personagem em questão, por conseguinte, os elementos criados possibilitam a incorporação de vários aspectos da vida, das emoções, das percepções, mentalidade dos personagens e muito do contexto em que a se passa a obra.

A narrativa histórica se preocupa com os aspectos possíveis de se observar a partir das fontes, muitas vezes é difícil apresentar sentimentos, emoções, facetas da personalidade dos sujeitos históricos, já na Literatura isso é aceitável, desprendida do compromisso com as fontes, há a abertura para a construção imaginária, trazendo situações, sentimentos, pensamentos, personificando os personagens da obra e da época. 
Partindo dessa premissa há no cruzamento entre História e Literatura um potencial vasto que possibilita compreender o passado e imaginar questões peculiares de cada cotidiano a sua época. Adiante, apresentamos uma tentativa de compreensão da sociedade brasileira, tomando como exemplo as peculiaridades da Bahia na metade do século $\mathrm{XX}$, partindo da conversa entre a historiografia e a Literatura sobre o tema. Usamos como fonte a produção literária: A morte e a morte de Quincas Berro Dágua (1959), de Jorge Amado. Nossa proposta é historicizar a obra literária, tomando-a como testemunho histórico (CHALHOUB; PEREIRA, 1998).

\section{Literatura enquanto fonte histórica: $A$ morte e a morte de Quincas Berro Dágua (Jorge Amado)}

Para decidirmos qual seria nossa fonte de análise, pesquisamos quais os títulos e autores sugeridos nos editais de vestibulares dos anos de 2013 a 2016, de duas universidades paranaenses: Universidade Estadual de Ponta Grossa - UEPG e Universidade Estadual do Centro-Oeste do Paraná UNICENTRO. Nesse levantamento, percebemos que as obras, recorrentemente citadas, eram de três autores:

Tabela 1: Autores e obras mais citadas nos editais para vestibulares

\begin{tabular}{|c|c|c|}
\hline Autor & Obras & Ano dos editais \\
\hline \multirow{3}{*}{$\begin{array}{c}\text { Machado de } \\
\text { Assis }\end{array}$} & Dom Casmurro & $\begin{array}{c}\text { 2014-2015-2016 } \\
\text { (UNICENTRO) }\end{array}$ \\
\cline { 2 - 3 } & Memórias de Aires & $\begin{array}{c}2014-2015-2016 \\
\text { (UNICENTRO) }\end{array}$ \\
\cline { 2 - 3 } & Várias Histórias & 2014-2015-2016 \\
& (UNICENTRO) \\
\hline \multirow{2}{*}{ Jorge } & $\begin{array}{c}\text { A morte e a Morte de } \\
\text { Quincas Berro Dágua; }\end{array}$ & 2016 (UEPG) \\
\cline { 2 - 3 } & Capitães de areia & 2015-2016 (UNICENTRO) \\
\hline
\end{tabular}




\begin{tabular}{|l|c|c|}
\hline $\begin{array}{l}\text { Mário de } \\
\text { Andrade }\end{array}$ & $\begin{array}{c}\text { Amar, } \\
\text { intransitivo }\end{array}$ & 2016 (UEPG) \\
\cline { 2 - 3 } & Contos Novos & $2013 / 2014$ (UEPG) \\
\hline
\end{tabular}

Fonte: Elaborado pelos autores com dados retirados dos editais de vestibulares das duas instituições de 2013 a 2016.

A validade e potencial das obras e autores são inquestionáveis, contudo, diante da necessidade de um recorte possível, Jorge Amado nos chama atenção, já que fora o único sugerido pelas duas Instituições de Ensino Superior, por isso o escolhemos. Definido o autor, elegemos como fonte a obra $A$ morte e a morte de Quincas Berro Dágua, encomendada pela Revista Senhor e publicada em 1959. Um romance traduzido para vários idiomas adaptado para teatro, televisão e cinema, além de ser sugestão no edital mais recente dos analisados ${ }^{5}$.

Jorge Amado, nascido no dia 10 de agosto de 1912 em Itabuna, cidade da Bahia, é reconhecido por suas obras literárias como um dos principais representantes do romance regionalista de seu estado e do Brasil. Desde a adolescência, escreveu seguindo o estilo de romance modernista, notado, inclusive, internacionalmente. Jorge Amado lutou para ser considerado um "escritor popular", o foco de sua escrita sempre esteve vinculado ao cotidiano do "povo e à gente simples", sendo esses os personagens principais de seus enredos (PALAMARTCHUK, 1998).

A Literatura contribui para percebermos questões próprias do momento histórico vivido e retratado pelo autor, assim:

\footnotetext{
É recorrente nos primeiros romances de Amado a tentativa de reinterpretação histórica do país. Ainda que essa tentativa apareça de forma crescente nesses romances, sua versão da história pretende colocar no centro das narrativas personagens populares, o que pode ajudar a revelar um projeto social do autor. Mas para entender a sua nova versão da história do Brasil e seus sujeitos, é preciso, antes de mais nada, perceber qual o papel social que o autor define logo de início para si (PALAMARTCHUK, 1998, p. 336).
}

\footnotetext{
${ }^{5}$ Necessário frisar que todas as obras sugeridas possuem potencial para serem analisadas enquanto fonte histórica, porém neste artigo não conseguiríamos contemplar todas, por isso fizemos a escolha por apenas uma.
} 
E esse "projeto social" revela as noções que o autor possui de povo e popular, ou seja, é possível compreender traços do próprio Jorge Amado na escrita. A morte e a morte de Quincas Berro Dágua, fora uma obra escrita na fase mais madura de Amado, portanto o autor já havia se distanciado das críticas mais ferrenhas a aspectos políticos:

Jorge Amado é o romancista da vida popular, que retratará em sua ficção a maneira de ser da população baiana, seus costumes, sonhos, e também suas misérias. No início de sua trajetória literária, Jorge Amado preocupou-se mais com os aspectos políticos da luta de sua gente. Ele próprio, como cidadão, engajou-se na luta política contra a ditadura de Getúlio Vargas, o que Ihe valeu prisão e exílio do país. Seus livros de conteúdo político chegaram a ser queimados em praça pública. Depois, afastou-se dessa ênfase política, enveredando para o registro dos costumes e a fantasia, bem ao gosto de seu público leitor (ABDALA JUNIOR, 1993, p. 32).

Amado deixa de criticar explicitamente a política, mas retrata dilemas, angústias e questões socialmente impostas no seu próprio cotidiano, com tom irônico e provocador. Por isso é importante situar autor e obra literária no tempo, compreendendo-os enquanto historicamente condicionados e inseri-los no movimento da sociedade (CHALHOUB; PEREIRA, 1998).

Na obra $A$ morte e a morte de Quincas Berro Dágua, cuja primeira edição é de 1959, Amado nos faz entrar na História e imaginar um baiano na metade do século $X X$ vivendo todas as nuances da moralidade e da imoralidade, regras e etiquetas do contexto social interpretado.

Jorge Amado vai, aos poucos, amadurecendo sua escrita e lança uma "proposta literária-missionária: educar e regenerar o povo, conscientizando seus personagens principais e revelando uma proposta de transformação social inerente à sua própria opção política" (PALAMARTCHUK, 1998, p. 340). Seus escritos estão permeados de preocupação social, atrelada a seus ideais comunistas e de bem estar social, presença marcada na obra $A$ morte e a morte de Quincas Berro Dágua, na qual retrata um cidadão socialmente aceito, porém infeliz na sua vida 
moralmente regrada, conduzida por ideias capitalistas de posses e finanças estáveis. Tal homem decide jogar tudo para o alto, esquecer as convenções sociais e a prioridade pelo dinheiro, assumindo uma vida de boêmio, sem obrigações e normas, anti-burguesa e feliz.

Quincas contraria os ideais de sua família, muito comuns para a época, tornando-se "desgosto e vergonha para a família", porém sua família refletia o que a sociedade baiana entendia como "certo", diante de um padrão socialmente construído do momento:

Assim é o mundo, povoado de céticos e negativistas, amarrados, como bois na canga, à ordem e a lei, aos procedimentos habituais e ao papel selado (AMADO, 1998, p.2).

A obra retrata as várias mortes do protagonista, que primeiro morrera para a sociedade, para a classe média da qual fazia parte, sendo o Joaquim Soares da Cunha apenas uma memória, sua transformação em Quincas foi entendida como vergonha para sua família. A narrativa de Jorge Amado inicia com a morte física de Joaquim, agora conhecido como Quincas Berro Dágua e todo o desenrolar de seu velório. Porém, sua família consanguínea, envergonhada com sua transformação, o matara muito antes, mesmo estando fisicamente vivo:

Era o cadáver de Quincas Berro Dágua, cachaceiro, debochado e jogador, sem família, sem lar, sem flores e sem rezas. Não era Joaquim Soares da Cunha, correto funcionário da Mesa de Rendas Estadual, aposentado após vinte e cinco anos de bons e leais serviços, esposo modelar, a quem todos tiravam o chapéu e apertavam a mão (AMADO, 1998, p. 14).

A opção de Joaquim por se jogar em uma vida "ínfima" não era compreendida por sua família de classe média conservadora, tanto que sua filha, sempre que possível, expressava sua vergonha e indignação, taxando seu pai como louco, algo que, para sua infelicidade, a medicina não conseguira provar. Uma mancha moral e social para a dignidade da família, sentimento representado na obra e que se fazia presente nas classes mais abastadas da sociedade brasileira conservadora da década de 1950. 
Quincas, portanto, era visto por sua família como aquele que infringe os códigos de boa conduta, perdendo o status de homem digno e decente tão estimado pela alta sociedade baiana da época "não era ele homem de respeito e de conveniência, apesar do respeito dedicado por seus parceiros de jogo a jogador de tão invejada sorte e a bebedor de cachaça tão longa e conversada" (AMADO, 1998, p. 3-4).

As classes antagônicas presentes na obra de Jorge Amado apresentam as características do contexto social da década de 1950, no Brasil, na qual advindo da política populista e autoritária de Vargas crescia o repúdio da classe média pelos pobres e miseráveis (MACIEL, 2006). Esse repúdio ao modo de vida dos menos abastados é notado em vários momentos da obra de Amado, como, por exemplo: "é memória de morto, como se sabe, é coisa sagrada, não é para estar na boca pouco limpa de cachaceiros, jogadores e contrabandistas de maconha [...] vagabundos" (1998, p. 8-9). Esse tipo de construção social do "outro", com ataques diretos e injustos, perpetuou-se em relação ao baiano que até hoje sofrem com estereótipos ligados às suas condutas.

Esses sentimentos íntimos dos homens e mulheres de outros tempos são importantíssimos para a compreensão de uma época e de como surgem e se propagam ideias preconceituosas, como estereótipos e estigmas, que devem ser descontruídos. E neste sentido a Literatura muito acrescenta, já que "literatura e literatos [...] são sujeitos e personagens das histórias que contam" (CHALHOUB; PEREIRA, 1998, p. 8).

É possível perceber alguns estereótipos que são tratados pelo autor na obra. O ex-militar, cabo Martin, por exemplo, envergonhou a farda (sentimento de patriotismo) e o que lhe restava era "altivez de mulato boa pinta e a agilidade de suas mãos no baralho [...] sem falar em sua capacidade no violão" (AMADO, 1998, p. 55), coisa de malandro, que não tem disposição ao trabalho, essa imagem estereotipada fora edificada por um discurso preconceituoso, histórica e socialmente forjado (MEIRA; HEINE, 2013). 
Nesse sentido, o próprio personagem principal carrega elementos do estereótipo de "baianidade", mesmo morto Quincas é sarcástico e debochado. Além dele, Negro Pastinha, personagem amigo das noitadas de Quincas, representa a ideia preconcebida da sexualidade a flor da pele que o baiano/baiana "naturalmente têm", quando é, de fato, mais uma representação estereotipada de baianidade (MEIRA, 2015).

Os amigos de Quincas pontuavam a petulância da família do falecido "aquela família de Quincas, tão metida a sebo, revelara-se mesquinha e avarenta" (AMADO, 1998, p. 73), isso porque apresentavam um Joaquim (ao invés de Quincas) no caixão, mas não serviam, nem ofereciam nada às pessoas que por ali estavam. Por outro lado, os amigos de Quincas já disputavam sua herança, sua companheira Quitéria do olho arregalado, seu único bem. Jorge Amado retrata, assim, as nuances das personalidades dos personagens, que oscilavam entre o "certo" e o "errado" dentro do padrão socialmente aceito da época.

Ao cair da noite, Quincas fica na companhia dos "vagabundos" (como sua filha os chamava). Na primeira oportunidade, retiraram 0 defunto do caixão e seguiram com ele pelos lugares diariamente frequentados pelo grupo de amigos. Nesse momento, o autor, Jorge Amado, descreve a noitada de viagem no saveiro (embarcação de madeira) toda a alegria, festança, bebedeiras e algumas confusões da última noite de Quincas Berro Dágua, ao "estilo baiano". Com muitas emoções, inclusive uma tempestade, Quincas despede-se do mundo físico como um "bom baiano", contestando e mostrando resistência. Segundo o que dizem, pronunciou sua frase derradeira: "- Me enterro como entender / Na hora que resolver. / Podem guardar seu caixão, / Pra melhor ocasião. / Não vou me deixar prender / Em cova rasa no chão" (AMADO, 1998, p. 96).

Sequer quando morre Quincas Berro Dágua deixa que os outros determinem seu local, muito menos sua vestimenta, ornamentação e posição. Quincas resiste ao que Ihe é imposto socialmente, seguindo suas convicções até depois de morto.

\section{Considerações finais}


A História e a Literatura são campos distintos e convergentes, desta forma nosso esforço neste texto fora trazer algumas maneiras possíveis de aproximação e diálogo dessas áreas. A partir dos anos 1970, posteriormente à reforma na historiografia, a terceira geração dos Annales dá início ao debate entre História e Literatura, da qual se apropria enquanto fonte para a compreensão das mentalidades sociais.

Os historiadores da vertente historiográfica, decorrente do movimento da escola dos Annales, denominada História Cultural, fazem grande uso da Literatura em seus escritos, movimento que deriva da abertura historiográfica para novas fontes, objetos e abordagens.

Especificamos as diferenças e singularidades dos dois campos tratados, sendo que ambos têm, no passado e na sociedade, seus objetos narrativos. Contudo, a História tem por obrigação a investigação amarrada ao método, que permite analisar a fonte e construir, a partir dela, uma narrativa sobre o passado aceitável cientificamente. Questão essa não obrigatória no trabalho do literato que, por sua vez, dentro das questões metodológicas de seu campo, não tem a necessidade de prender-se à fonte, podendo criar e imaginar o acontecimento.

Tomamos a Literatura enquanto testemunho histórico, como qualquer outro documento, que produz evidência histórica, validado enquanto fonte. $E$, como fonte, dela desconfiamos, colocamos à prova e buscamos vestígios do passado. Ao fim, propusemos a análise de uma obra literária, de cunho popular, como o próprio autor intitula.

A obra A morte e a Morte de Quincas Berro Dágua (1958), de Jorge Amado, de forma irônica e sarcástica desperta o leitor, com ar de riso durante a leitura, para compreender um contexto com maior amplitude que o dia do enterro de Quincas Berro Dágua (ou Joaquim). A partir da exposição dos dois mundos extremos, vividos pelo personagem, pudemos identificar aspectos de duas classes sociais: da média e da baixa - Ricos $X$ Pobres, economia: Capitalismo X Comunismo (ou anarquismo), e de 
sentimentos, mentalidades e padrões sociais que não são fixos, como tudo no romance e na vida real.

A avareza e a generosidade, humildade e arrogância, amor e ódio, obrigação e liberação, moralidade e imoralidade, normas e ilegalidade, nuances de sentimentos e percepções de mundo, presentes no romance, que possibilitam compreender muito mais das noções de "baianidade" na qual forjaram-se discursos e construíram-se estereótipos e estigmas sobre a população baiana que, infelizmente, ainda perpetuam na sociedade.

De forma alguma pretendemos uma verdade absoluta, ou uma única interpretação da obra literária utilizada, muito menos das apropriações e distâncias dos campos apresentados neste estudo, Literatura e História, já que percebemos a complexidade e grandiosidade dessa forma de interpretar a sociedade. Possuímos a consciência de que, para nós, esse é apenas um início de debate.

\section{Referências}

Fonte:

AMADO, Jorge. A morte e a morte de Quincas Berro Dágua. 77. ed. Rio de Janeiro: Record, 1998.

\section{Bibliografia:}

ARISTÓTELES. A arte poética. Disponível em: https://ava.uepg.br/pos/pluginfile.php/65100/mod book/chapter/8267/PO \%C3\%89TICA\%2C\%20de\%20Arist\%C3\%B3teles.pdf. Acesso em: 25 fev. 2019.

ARISTÓTELES. Poética. São Paulo: Nova Cultural, 2000.

ASSIS, Gabriella Lima de; CRUZ, Marcus Silva da. Desconstruindo a História: Hayden White e a escrita da narrativa. Revista Mosaico, v. 3, n. 1, p. 111-118, jan./jun. 2010. Disponível em:

http://seer.pucgoias.edu.br/index.php/mosaico/article/download/1837/114 1. Acesso em: 25 fev. 2019.

BARROS, José Costa D'Assunção. Jacques Le Goff: considerações sobre contribuição para a teoria da história. Cadernos de História, Belo Horizonte, v. 14, n. 21, p. 135-156, 2013. Disponível em:

http://periodicos.pucminas.br/index.php/cadernoshistoria/article/view/5074 . Acesso em: 25 fev. 2019. 
BURKE, Peter. A escola dos Annales (1929-1989): A Revolução Francesa da historiografia. São Paulo: Editora Universidade Estadual Paulista, 1991.

CAMILOTTI, Virgínia; NAXARA, Márcia Regina C. História e literatura: fontes literárias na produção historiográfica recente no Brasil. História: Questões \& Debates, v. 50, n. 1, 2009.

CHALHOUB, Sidney. A História nas histórias de Machado de Assis: uma interpretação de Helena, IFCH/UNICAMP, São Paulo, 1991.

CHALHOUB, Sidney; PEREIRA, Leonardo A. de Miranda. A história contada: capítulos de história social da literatura no Brasil. Rio de Janeiro: Nova Fronteira, 1998.

FONSECA, Selva Guimarães. Didática e prática de ensino de história: Experiências, reflexões e aprendizados. Campinas: Papirus 2003.

ABDALA JUNIOR, Benjamin. O Romance social brasileiro. Scipicione, São Paulo, 1993.

LE GOFF, Jacques. A História Nova. Martins Fontes: São Paulo, 1990.

LE GOFF, Jacques. História e memória. UNICAMP: Campinas. 2003.

MACIEL; Bruno Bastos. Políticas Culturais no Estado da Bahia (1945-1964). Salvador, UFBA, 2006. Disponível em:

http://www.cult.ufba.br/arquivos/Pol ticas Culturais da Bahia $1945 \quad 19$ 64 Bruno III.pdf. Acesso em: 25 fev. 2019.

MEIRA, Reginete de Jesus Lopes. Entre a alegria e a preguiça: a construção discursiva da baianidade na publicidade de turismo. 2015. $140 \mathrm{f}$.

Dissertação (Mestrado em Estudos Linguísticos) - Universidade Estadual de Feira de Santana, Feira de Santana, 2015. Disponível em:

http://tede2.uefs.br:8080/handle/tede/379. Acesso em: 25 fev. 2019.

MEIRA, Reginete de Jesus Lopes. O caricato do baiano: representação discursiva em anúncios de turismo. Revista Pandora Brasil, n. 58, set. 2013.

MORAES, Dislane Zerbinatti. Literatura e história na escola: aprendizagens e desafios mútuos. Simpósio Nacional de Letras e Linguística. 2009. p. 120

NASCIMENTO; Jairo Carvalho do. A literatura de cordel no ensino de História: reflexões teóricas e orientações metodológicas. ANPUH - XXIII Simpósio Nacional de História - Londrina, 2005. Disponível em: http://anais.anpuh.org/wp-content/uploads/mp/pdf/ANPUH.S23.0477.pdf. Acesso em: 25 fev. 2019. 
PALAMARTCHUK, Ana Paula. Jorge Amado: um escritor de putas e vagabundos? (p. 333-360). In: CHALHOUB; PEREIRA. A história contada: capítulos de história social da literatura no Brasil. Rio de Janeiro: Nova Fronteira, 1998.

PESAVENTO, Sandra Jatahy. Contribuição da história e da literatura para a construção do cidadão: a abordagem da identidade nacional. In: Discurso histórico e narrativa literária. Jacques Leenhardt, Sandra Jatahy Pesavento (orgs.). Campinas, SP: Editora da UNICAMP, 1998. p. 17-41.

PESAVENTO, Sandra Jatahy. Correntes, campos temáticos e fontes: uma aventura da História. In: Idem. História \& História Cultural. Belo Horizonte: Autêntica, 2004.

RÜSEN, Jörn. Razão Histórica: teoria da história: fundamentos da ciência histórica. Brasília: Editora: Universidade de Brasília, 2001.

RÜSEN, Jörn. Teoria da História: uma teoria da história como ciência. Curitiba, editora UFPR, 2015.

SANTOS, A. F; SIMON, C.B. A literatura no ensino de história: 30 anos de pesquisas. IN: VII SEPECH - Seminário de Pesquisa em Ciências Humanas. Londrina, EDUEL, 2008.

SANTOS, A. F; SIMON, C.B. Entre fatos e artefatos: literatura e ensino de História nos encontros acadêmicos nacionais (1979-2007). Dissertação (Mestrado em História Social). Universidade Estadual de Londrina. Londrina, 2009. Disponível em:

http://www.bibliotecadigital.uel.br/document/?code $=$ vtls000149998. Acesso em: 25 fev. 2019.

SOISTAK, Angelis Cristina; OLIVEIRA, Silvana. Literatura e História: Ficção e Discurso Histórico em José Saramago (p. 51-99). In: Especialização em História, Arte e Cultura: livro 3 por Rosângela Wosiack Zulian e outros. Ponta Grossa: UEPG/NUTEAD, 2010. 253p. 